\title{
Experimental Analysis of a Triple Concentric Tube Heat Exchanger
}

\author{
Md. Anowar Hossain ${ }^{1}$, Muhammad Afaz Uddin ${ }^{2}$, Md. RashelHossen ${ }^{3}$, \\ Hasan Mohammad Mostofa Afroz ${ }^{4}$ \\ 1,2,3,4 Department of Mechanical Engineering, Dhaka University of Engineering \& Technology, Gazipur, \\ Bangladesh
}

*Corresponding Author: Md. Anowar Hossain, Department of Mechanical Engineering, Dhaka University of Engineering \& Technology, Gazipur, Bangladesh

\begin{abstract}
In this experimental study, a triple concentric tube heat exchanger (TCTHE) is designed and fabricated which consists of three copper tubes of diameter $41.2 \mathrm{~mm}, 25.35 \mathrm{~mm}$ and $12.6 \mathrm{~mm}$ and the length of the tubes are $580 \mathrm{~mm}, 740 \mathrm{~mm}$ and $857 \mathrm{~mm}$, respectively. The thickness of the outer, middle and inner tubes are $1.25 \mathrm{~mm}, 0.94 \mathrm{~mm}$ and $0.80 \mathrm{~mm}$, respectively. The objective of this study is to reduce the length and material cost as well as increase the heat transfer surface area by adding an intermediate tube to the double concentric tube heat exchanger. The performance of the heat exchanger for different inlet temperatures and mass flow rates are estimated and analyzed. From the experimental results, it is found that the overall heat transfer coefficient is increased with increasing mass flow rate for hot and cold fluid. And also, overall heat transfer coefficient of the equivalent double concentric tube heat exchanger is compared with that of the TCTHE and found better performance. For the same heat transfer area, the length of the heat exchanger is $65.17 \%$ reduced compared to double tube heat exchanger.
\end{abstract}

Keywords: Heat exchanger, Triple concentric tube, Overall heat transfer coefficient, Logarithmic mean temperature difference.

\section{NOTATION}

A Heat transfer area $\left(\mathrm{m}^{2}\right)$

$C_{p}$ Specific heat $(\mathrm{J} / \mathrm{kg} \mathrm{K})$

$d \quad$ Diameter (m)

$k \quad$ Thermal conductivity

$\dot{m} \quad$ Mass flow rate (lit/sec)

$\operatorname{Pr} \quad$ Prandlt number

$\dot{Q} \quad$ Heat flow rate $(\mathrm{W})$

$R_{e}$ Reynolds number

$T$ Temperature $\left({ }^{\circ} \mathrm{C}\right)$

$U \quad$ Overall heat transfer coefficient $\left(\mathrm{W} / \mathrm{m}^{2} \mathrm{~K}\right)$

$U_{o l}$ Overall heat transfer co-efficient based on outside area of central tube $\left(\mathrm{W} / \mathrm{m}^{2} \mathrm{~K}\right)$

$U_{i 2}$ Overall heat transfer co-efficient based on inside area of middle tube $\left(\mathrm{W} / \mathrm{m}^{2} \mathrm{~K}\right)$

$\dot{v} \quad$ Volumetric flow rate $\left(\mathrm{m}^{3} / \mathrm{s}\right)$

$V \quad$ Linear velocity $(\mathrm{m} / \mathrm{s})$

$\rho$ Density $\left(\mathrm{kg} / \mathrm{m}^{3}\right)$

$\mu \quad$ Dynamic viscosity (Pa.s)

$\alpha$ Coefficient of heat transfer $\left(\mathrm{W} / \mathrm{m}^{2} \mathrm{~K}\right)$

$\Delta$ Difference 


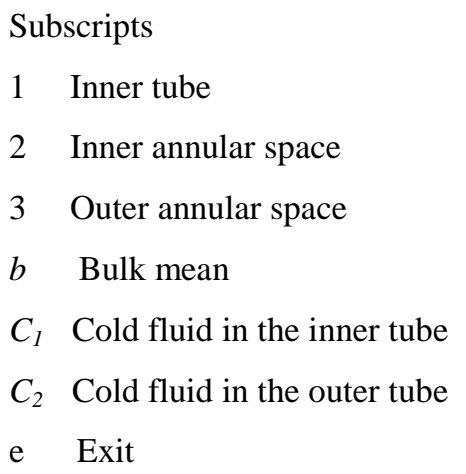

\section{INTRODUCTION}

Heat exchanger is used to transfer heat from one fluid to another. The basic component of a heat exchanger can be observed as a tube with one fluid running through it and another fluid flowing on the outside. The simple context of heat exchanger is one for which the hot and cold fluids move in the same or opposite directions in a concentric tube construction. In the parallel-flow arrangement, the hot and cold fluids enter at the same end, flow in the same direction, and leave at the same end. In the counter flow arrangement, the fluids enter at opposite ends, flow in opposite directions, and leave at opposite ends (Fig. 2). In the TCTHE, there are three sections: central tube, inner annular space and outer annular space. Heat transfer mediums are passed through the central tube and outer annular space and a thermal fluid is passed through an inner annular space as shown in Fig. 1.

Many researchers have been performed the design and analysis of double tube heat exchanger. Researchers have done theoretical as well as experimental analysis of TCTHE. A set of equations for design and performance analysis of TCTHE have been developed. From the available literatures, the major contributions of researchers are as follows: The well-known analytical equations for fluid temperatures at any axial location along the heat exchanger for parallel and counter flow configurations are established and conducted simulation work for the same heat exchanger by Zuritz [1].

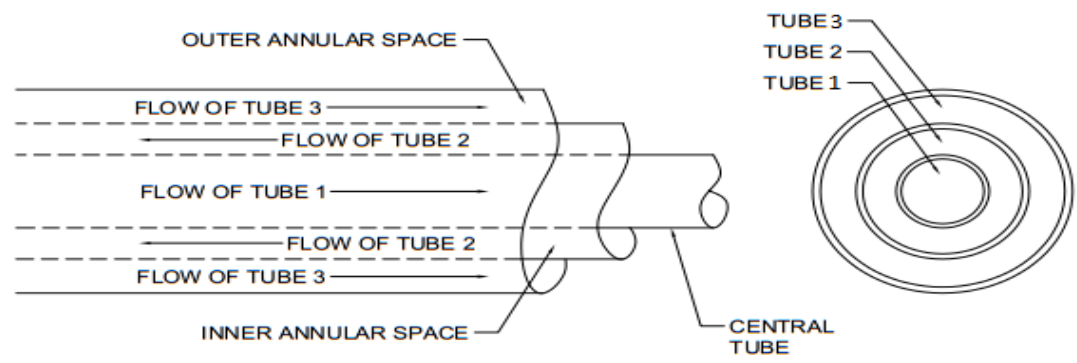

Fig1. Triple concentric tubes

The equations developed by Zuritz for heat losses to the surroundings are useful for design purposes. From their simulations, it is seen that the creation of an annular region within the inner tube increases the overall heat transfer efficiency and reduces the heat exchanger length requirement by almost $25 \%$.

Sekulic and Shah [2] offered in detail a review on the step-by-step thermal design theory for simplified heat exchanger rating and sizing problems of three fluid heat exchanger. They have allowed for third fluid temperature to vary according to main thermal communication while neglecting interaction with ambient. They use the effectiveness- NTU approach as well as LMTD approach for the developed of their theory for all flow arrangements for three-fluid heat exchangers.

A comprehensive theoretical study conducted on TCTHEs was carried out by Unal A.[3]. In his first part, a governing differential equation was developed together with possible solutions under simplified conditions for both counter-flow and parallel-flow arrangements. The equations derived in his study can be used for both design and performance calculations, besides they can be used for the determination of bulk temperature variation along the exchanger.

Unal A.[4] conducted several case studies on triple concentric-tube heat exchangers for counter-flow arrangement based on the solution obtained in the first part. He developed a computer program, 
TRIPLET, for computation purposes. It has been demonstrated for triple tube and the corresponding double tube counter-flow heat exchangers that: 1 ) the relative sizes of the tubes play a very important role on the exchanger performance and/or on the exchanger length. 2) Optimizing triple tube heat exchanger effectiveness provides a considerable amount of increase in the exchanger performance and considerable amount of savings in space and material when compared with a double tube heat exchanger with the same outer tube diameter.

Batmaz E.[5] developed a more generic way of calculating overall heat transfer coefficients and temperature profiles of the fluids in a triple tube heat exchanger for co-current flow arrangement using the energy balance equations on a control volume. He also compared the effective overall heat transfer coefficient and the effectiveness values for the TTHE with an equivalent (theoretical) double tube heat exchanger (DTHE). he found that found that the effectiveness of the co-current runs in a TTHE was not always greater than the effectiveness of the theoretical co-current runs in a DTHE. The cause for a decrease in the effectiveness in the TTHE was attributed to the crossover phenomenon that occurred during co-current runs.

Radulescu S. et al. [6a] developed an algorithm for the calculation of partial coefficient of heat transfer for a fluid which flows through an inner annular space of a TCTHE in transition regime based on experimental results. He established a new correlation for design purposes on heat transfer devices, such as TCTHE. The correlation obtained is:

$N u_{H}=2.718 \times R e_{H}^{0.597} \times P r_{H}^{1 / 3} \times\left(\frac{d_{h 2}}{L_{1}}\right)^{2 / 3}$

It molds the heat exchanger for Reynolds values that go from 2264 to 7893 and for the velocities values between 0.11 and $0.36 \mathrm{~m} / \mathrm{s}$. The practical applicability of the obtained correlation in the study applies for Prandtl values between 3.30 and 3.70. Radulescu S. et al. [6b] experimentally show that for the same length of the heat exchanger, the heat transfer area and the overall heat transfer coefficients for TTHE are higher than for DTHE.

Tejas Ghiwala[7] carried out a numerical analysis on sizing of triple tube heat exchanger. During the analysis, they compared triple tube heat exchanger with double tube heat exchanger. They found that the TCTHE shows better heat transfer efficiencies and large heat transfer area per unit exchanger length. And also, it reduces space requirement.

\section{STEP-BY-STEP DeSign Procedure FOR TCTHE}

In the present work, at first a TCTHE is designed by LMTD method by considering a known set of input values as given in table 1.Then by finding the length, drawing the TCTHE setup by using AutoCAD 2012 as shown in figure 2.

The step-by-step design procedure [7] as follows:

For steady state energy balance equation

$\dot{Q}_{H}=\dot{Q}_{c 1}+\dot{Q}_{c 2}$

Bulk mean temperature of water is determined by:

$\mathrm{T}_{\mathrm{b} 1}=\frac{T c 1 i+T c 2 e}{2}$

$\mathrm{T}_{\mathrm{b} 2}=\frac{T_{H i}+T_{H e}}{2}$

$T_{b 3}=\frac{T_{c 2 i}+T_{c 2 e}}{2}$

Properties of hot and cold water corresponding to bulk mean temperature that are used for design calculations given in table 2 .

Table1. Known input parameters for sizing calculation

\begin{tabular}{|c|c|}
\hline Input parameters & Values \\
\hline Hot water inlet temperature, $T_{H i}$ & $60^{\circ} \mathrm{C}$ \\
\hline
\end{tabular}




\begin{tabular}{|c|c|}
\hline Hot water outlet temperature, $T_{H e}$ & $43^{\circ} \mathrm{C}$ \\
Cold water $C_{1}$ inlet temperature, $T_{C 1 i}$ & $25^{\circ} \mathrm{C}$ \\
Cold water $\mathrm{C}_{2}$ inlet temperature, $T_{C 2 i}$ & $25^{\circ} \mathrm{C}$ \\
Mass flow rate of cold water, $\dot{m}_{c 1} \& \dot{m}_{c 2}$ & $0.0278 \mathrm{lit} / \mathrm{sec}$ \\
Mass flow rate of hot water, $\dot{\mathrm{m}}_{H}$ & $0.0417 \mathrm{lit} / \mathrm{sec}$ \\
Diameter of central tube, $\mathrm{d}_{\text {in1 }}$ & $11 \mathrm{~mm}$ \\
Diameter of intermediate tube, $\mathrm{d}_{\text {in } 2}$ & $23.5 \mathrm{~mm}$ \\
Diameter of outer tube, $\mathrm{d}_{\mathrm{in} 3}$ & $38.7 \mathrm{~mm}$ \\
Specific heat of hot water, $C_{P h}$ & $4182 \mathrm{~J} / \mathrm{kg} . \mathrm{K}$ \\
Thermal conductivity of copper, $K_{\text {copper }}$ & $401 \mathrm{~W} / \mathrm{m}$. \\
\hline
\end{tabular}

Table2. Properties of water corresponding to bulk mean temperature

\begin{tabular}{|l|c|c|}
\hline \multicolumn{1}{|c|}{ Properties } & At $31.35^{\circ} \mathrm{C}$ & At $51.5^{\circ} \mathrm{C}$ \\
\hline Density, $\rho\left(\mathrm{kg} / \mathrm{m}^{3}\right)$ & 995.04 & 987.34 \\
\hline Thermal conductivity, $k(\mathrm{~W} / \mathrm{m} . \mathrm{K})$ & 0.622 & 0.646 \\
\hline Specific heat, $C_{p}(\mathrm{~J} / \mathrm{kg} . \mathrm{K})$ & 4174.8 & 4176.35 \\
\hline Viscosity, $\mu(\mathrm{Pa} . \mathrm{s})$ & $7.8 \times 10^{-4}$ & $5.39 \times 10^{-4}$ \\
\hline Prandtl number, $P r$ & 5.23 & 3.48 \\
\hline
\end{tabular}

Linear velocity of normal supplied water (cold water) is calculated as:

$V_{C l}=\frac{\dot{m}_{c 1} \times 4}{\rho_{c 1} \times \pi \times d_{i n 1}^{2}}$

$V_{C 2}=\frac{\dot{m}_{c 2} \times 4}{\rho_{c 2} \times \pi \times\left(d_{\text {in } 3}^{2}-d_{\text {out } 2}^{2}\right)}$

Linear velocity of process water (hot water) is determined by

$V_{H}=\frac{\dot{m}_{H} \times 4}{\rho_{H} \times \pi \times\left(d_{\text {in } 2}^{2}-d_{\text {out } 1}^{2}\right)}$

Hydraulic diameter of water

$d_{h 2}=d_{\text {in } 2}-d_{\text {out } 1}$

$d_{h 3}=d_{\text {in } 3}-d_{\text {out } 2}$

Reynolds number for cold water is calculated by,

$\operatorname{Re}_{\mathrm{c} 1}=\frac{\rho_{c 1} \times W_{c 1} \times d_{i n 1}}{\mu_{c 1}}$

$\operatorname{Re}_{\mathrm{c} 2}=\frac{\rho_{c 2} \times W_{c 2} \times d_{h 3}}{\mu_{c 2}}$

Reynolds number for hot water is calculated by,

$\operatorname{Re}_{\mathrm{H}}=\frac{\rho_{H} \times W_{H} \times d_{h 2}}{\mu_{H}}$

In this research, $N u$ calculated for different flow situation, such as for laminar flow condition $(\operatorname{Re}<$ 2300) $\mathrm{Nu}$ calculated as,

$N u_{c}=0.51 \times R e_{c}^{0.5} \times P r_{c}^{1 / 3} \times\left(\frac{P r_{c}}{P r_{w}}\right)^{0.25}$

where $\left(\frac{P r_{c}}{P r_{w}}\right)^{0.25}$ is considered as 1 for same fluid flow. 
for the $R e$ values from 2300 to 4000 ,i.e.transition regime, $N u$ calculated as,

$N u_{H}=2.718 \times R e_{H}^{0.597} \times \operatorname{Pr}_{H}^{1 / 3} \times\left(\frac{d_{h 2}}{1.193}\right)^{2 / 3}$

For turbulence regime, Re values ranges between 3000 and $5 \times 10^{6}$, Gnielinski correlation is applicable forPrandlt number in between 0.5 and 2000.

$N u_{c l}=\frac{(f / 2) \times\left(R e_{c 1}-1000\right) \times P r_{c 1}}{1+12.7(f / 2)^{0.5} \times\left(P r_{c 1}{ }^{2 / 3}-1\right)}$

where the Darcy friction factor,

$f=\left(1.58 \ln \left(R e_{c 1}\right)-3.28\right)^{-2}$

The convective heat transfer co-efficient calculated from following equation:

$\alpha_{c 1}=\frac{N u_{c 1} \times k_{c 1}}{d_{i n 1}}$

$\alpha_{H}=\frac{N u_{H} \times k_{H}}{d_{h 2}}$

$\alpha_{c 2}=\frac{N u_{c 2} \times k_{c 2}}{d_{h 3}}$

\subsection{Overall Heat Transfer Co-Efficient}

There are two overall heat transfers co-efficient in TCTHE and one is for inner annular space and another is for outer annular space as shown in Fig. 1.

$\frac{1}{U_{o 1}}=\frac{d_{\text {out } 1}}{d_{\text {in } 1 \alpha_{c 1}}}+\frac{d_{\text {out } 1} \ln \left(d_{\text {out } 1} / d_{\text {in } 1}\right)}{2 k_{\text {copper }}}+\frac{1}{\alpha_{H}}$

$\frac{1}{\mathrm{U}_{\mathrm{i} 2}}=\frac{\mathrm{d}_{\text {in } 2}}{\mathrm{~d}_{\text {out } 2 \alpha_{\mathrm{c} 2}}}+\frac{\mathrm{d}_{\text {in } 2} \ln \left(\mathrm{d}_{\text {out } 2} / \mathrm{d}_{\text {in } 2}\right)}{2 \mathrm{k}_{\text {copper }}}+\frac{1}{\alpha_{\mathrm{H}}}$

The logarithmic mean temperature difference is calculated as,

$\Delta T_{l m 1}=\frac{\left(T_{H i}-T_{c 1 e}\right)-\left(T_{H e}-T_{c 1 i}\right)}{\ln \left(T_{H i}-T_{c 1 e} / T_{H e}-T_{c 1 i}\right)}$

$\Delta T_{\operatorname{lm} 2}=\frac{\left(T_{H i}-T_{c 2 e}\right)-\left(T_{H e}-T_{c 2 i}\right)}{\ln \left(T_{H i}-T_{c 2 e} / T_{H e}-T_{c 2 i}\right)}$

\subsection{Heat Transfer Rates}

Heat transfer rate of hot water is calculated as,

$\dot{Q}_{H}=m_{H} \times C_{P H} \times\left(T_{H i}-T_{H e}\right)$

Heat transfer rate of cold water $C_{1}$ is calculated as,

$\dot{Q}_{c 1}=m_{c 1} \times C_{P c 1} \times\left(T_{c 1 e}-T_{c 1 i}\right)$

Heat transfer rate of cold water $C_{2}$ is determined by,

$\dot{Q}_{c 2}=m_{c 2} \times C_{P c 2} \times\left(T_{c 2 e}-T_{c 2 i}\right)$

\subsection{Length of TCTHE}

The heat exchanger length can be calculated from the heat balance equation, which is given below:

$$
\begin{aligned}
& \dot{m}_{H} \times C_{P H} \times\left(T_{H i}-T_{H e}\right)=U_{o 1} A_{o 1} \Delta T_{l m 1}+U_{i 2} A_{i 2} \Delta T_{l m 2} \\
& \quad \Rightarrow \dot{m}_{H} \times C_{P H} \times\left(T_{H i}-T_{H e}\right)=U_{o 1} \pi d_{o 1} L \Delta T_{l m 1}+U_{i 2} \pi d_{i 2} L \Delta T_{l m 2}
\end{aligned}
$$

\subsection{Pressure Drop}

Pressure drop of hot and cold fluid is calculated by the following equations and checked the allowable pressure within 10 psi.

Frictional pressure loss, $\Delta f_{1}=\frac{4 f l v^{2}}{2 g d}$ 
Entrance and exit pressure losses, $\Delta f_{2}=\frac{v^{2}}{2 g}$

Total pressure drop, $\Delta P=\Delta f_{1}+\Delta f_{2}$

\subsection{Equivalent Double Tube Heat Exchanger}

Logarithmic mean area of double tube heat exchanger is equal to sum of the two logarithmic mean area of triple tube heat exchanger.

$$
\begin{aligned}
& A_{\text {lm } 1}=\pi \times \frac{d_{\text {out } 1}-d_{\text {in } 1}}{\ln \left(d_{\text {out } 1} / d_{\text {in } 1}\right)} \times L \\
& A_{\text {lm } 2}=\pi \times \frac{d_{\text {out } 2}-d_{\text {in } 2}}{\ln \left(d_{\text {out } 2} / d_{\text {in } 2}\right)} \times L \\
& A_{\text {lm }}=A_{\text {lm } 1}+A_{\text {lm } 2}
\end{aligned}
$$

Mass flow rate of cold water in equivalent double tube heat exchanger is equal to sum of mass flow rate of two cold water streams $\mathrm{C}_{1}$ and $\mathrm{C}_{2}$,

$\dot{m}_{c}=\dot{m}_{c 1}+\dot{m}_{c 2}$

For the same temperature drop of hot water, the outlet temperature of cold water is obtained by the energy balance equation,

$\dot{m}_{H} \times C_{P H} \times\left(T_{H i}-T_{H e}\right)=\dot{m}_{c} \times C_{P c} \times\left(T_{c e}-T_{c i}\right)$

And the logarithmic mean temperature difference is:

$\Delta T_{l m}=\frac{\left(T_{H i}-T_{c e}\right)-\left(T_{H e}-T_{c i}\right)}{\ln \left(T_{H i}-T_{c e} / T_{H e}-T_{c i}\right)}$

Heat transfer rate is calculated by,

$\dot{Q}=\dot{m}_{H} \times C_{P H} \times\left(T_{H i}-T_{H e}\right)$

To calculate overall heat transfer co-efficient in equivalent double tube heat exchanger, we use equation

$U=\frac{\dot{Q}}{A_{l m} \times \Delta T_{l m}}$

Length of double tube heat exchanger is determined by,

$A_{l m}=\pi \times d_{\text {in }} \times L_{D T H E}$

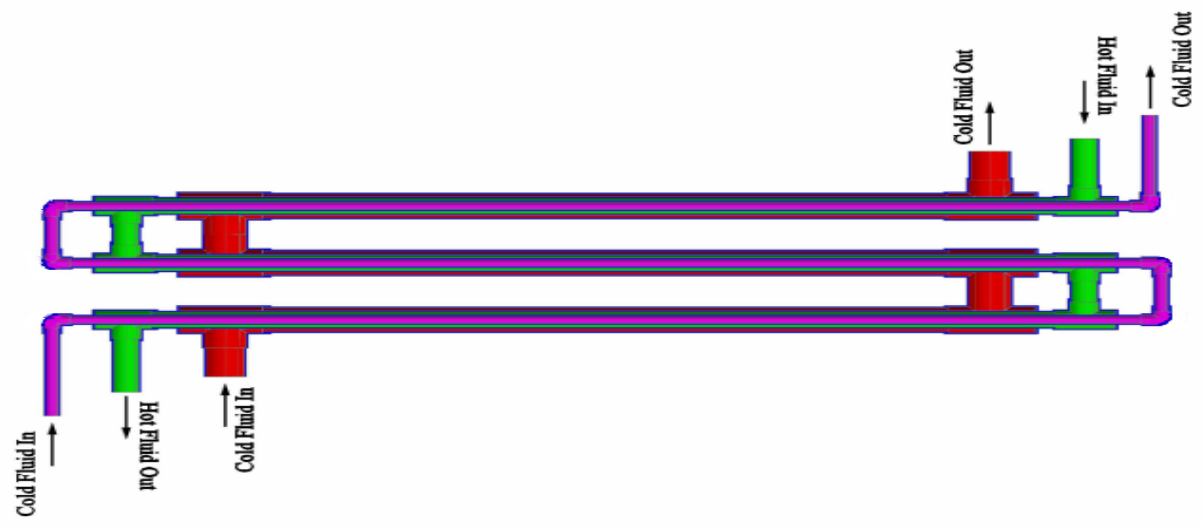

Fig2. Sectional view of designed counter flow TCTHE

\section{EXPERIMENTAL SET-UP}

Figure 2 shows, three different size copper tubes have been used that have the diameters of $41.2 \mathrm{~mm}$, $25.35 \mathrm{~mm}$ and $12.6 \mathrm{~mm}$ and the length are $580 \mathrm{~mm}, 740 \mathrm{~mm}$ and $857 \mathrm{~mm}$, respectively. The thickness of the tubes are $1.25 \mathrm{~mm}, 0.94 \mathrm{~mm}$ and $0.80 \mathrm{~mm}$, respectively. The copper tubes were wrapped by insulation to retard the heat transfer to the surrounding. To precisely investigate the temperature of the 
water twelve K-type thermocouples (four of each tube) were placed at various location along the length of heat exchanger. A 1500 Watts capacity immersion heater was used in the water tank to rise the temperature of the water in order to prepare the process water. To maintain the certain temperature of the process water a temperature controller was also used in the process water tank. A centrifugal pump $(0.5 \mathrm{hp})$ is used to flow the hot water. Moreover, three water control valves were used at the inlet of the three heat exchanger tubes, so that flow rate through the different tubes can be easily controlled. The details photograph of the experimental setup is shown in Fig. 3.

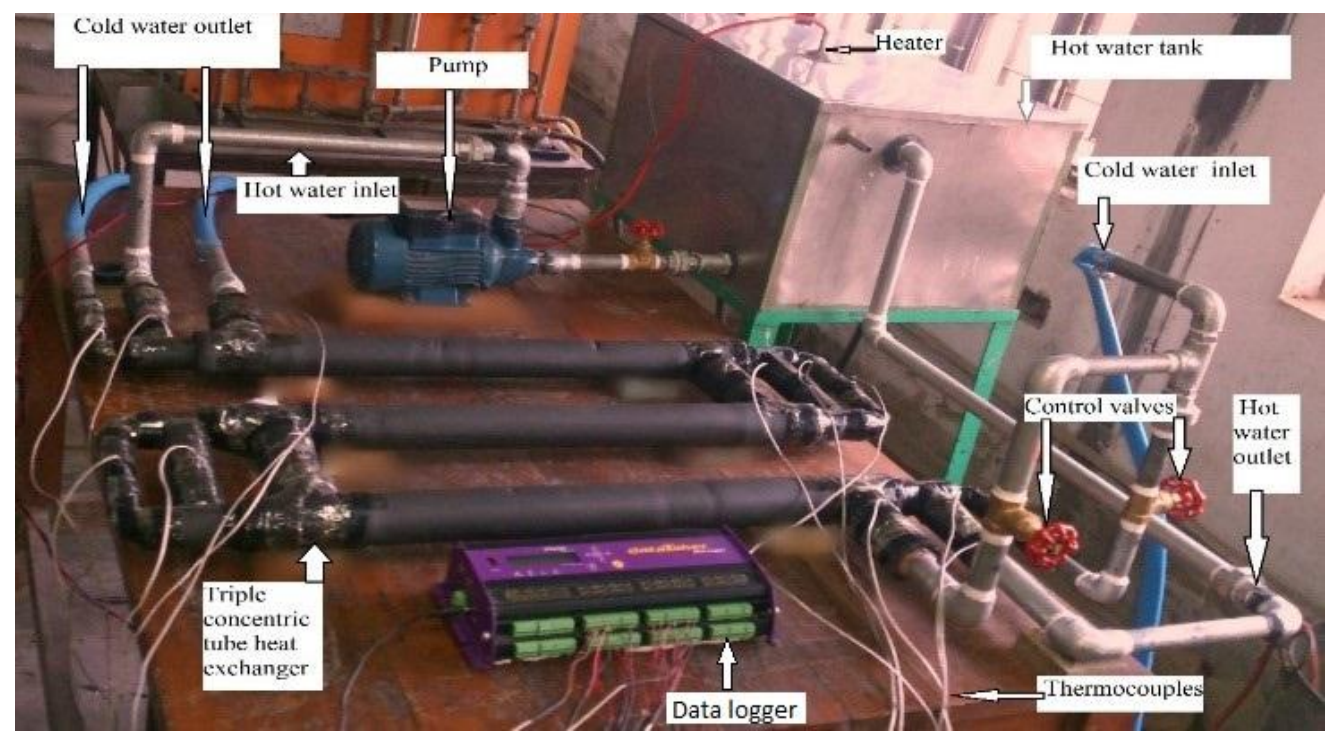

Fig3. Photograph of experimental set-up

The normal supply water is flowing through central and outer most tube and hot water is flowing through intermediate tube. The flow is controlled by using water flow control valve. A data logger is used to record the temperature variation inside the TCTHE.

\section{RESULTS AND DISCUSSION}

In the present experimental analysis, a triple concentric tube heat exchanger is developed. By changing mass flow rate of water, the temperature variation along the tube is recorded and plotted in figs. $4(\mathrm{a}-\mathrm{d})$. From figs. 4 (a, c \& d), it is observed that at the inlet of tube 1 and tube 3, temperatures are same but at the outlet $T_{\mathrm{c} 1}$ is higher than $T_{\mathrm{c} 2}$, this is may be because of turbulence present in tube 1 and tube 2 and laminar in tube 3 as seen in table 3 of experimental Reynolds number values. Different situation is seen in Fig. 4 (b), where $T_{c l}$ and $T_{c 2}$ are increased but the values are almost same. This is because of larger surface area contact with hot water and the velocity of fluid in tube 3 is very much lower than tube 1 .

Table3. Experimental Re values found out by changing the mass flow rate

\begin{tabular}{|c|c|c|c|}
\hline Number of Test & $\begin{array}{c}\text { Central tube } \\
\text { (Tube 1) }\end{array}$ & $\begin{array}{c}\text { Inner annular space } \\
\text { (Tube 2) }\end{array}$ & $\begin{array}{c}\text { Outer annular space } \\
\text { (Tube 3) }\end{array}$ \\
\hline 1 & 4439.83 & 2644.95 & 758.45 \\
\hline 2 & 9693.04 & 5617.00 & 1675.10 \\
\hline 3 & 17413.72 & 14742.89 & 1553.80 \\
\hline 4 & 16658.59 & 13842.87 & 5056.20 \\
\hline
\end{tabular}

Fig. 5 shows the variation of overall heat transfer coefficient with mass flow rate. The overall heat transfer coefficients are obtained by experimentally by changing mass flow rate. It is observed that overall heat transfer coefficients are increases with mass flow rate. The overall heat transfer coefficient between cold water of central tube and hot water of intermediate tube was found of 658.89 $\mathrm{W} / \mathrm{m}^{2} \mathrm{~K}$ as well as overall heat transfer coefficient between cold water of outer tube and hot water of intermediate tube was found of $595.83 \mathrm{~W} / \mathrm{m}^{2} \mathrm{~K}$. On the other hand, the overall heat transfer coefficient $(U)$ in equivalent double tube heat exchanger was found of $618.6 \mathrm{~W} / \mathrm{m}^{2} \mathrm{~K}$ which is less than the average eheat transfer coefficient of TCTHE. The details overall heat transfer coefficient values corresponding to mass flow rate is given in table 4 . 


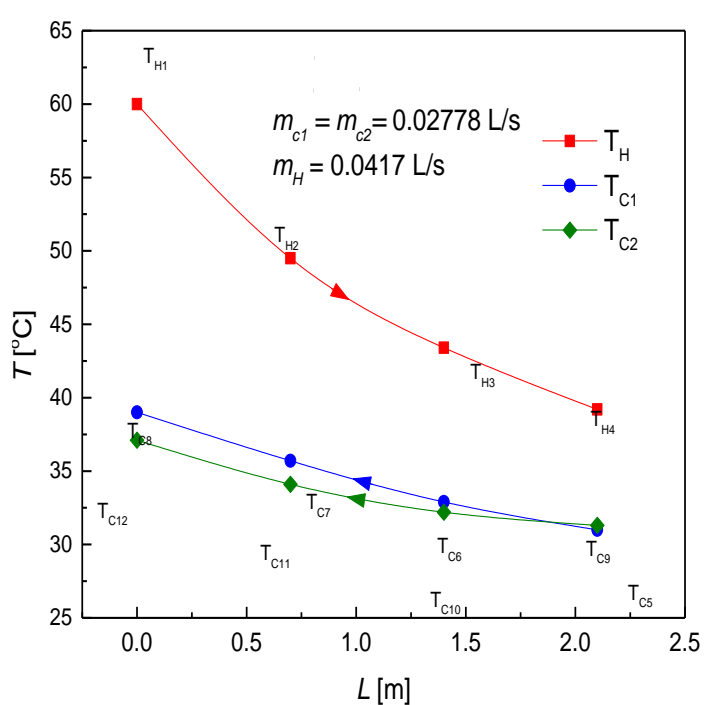

(a)test 1

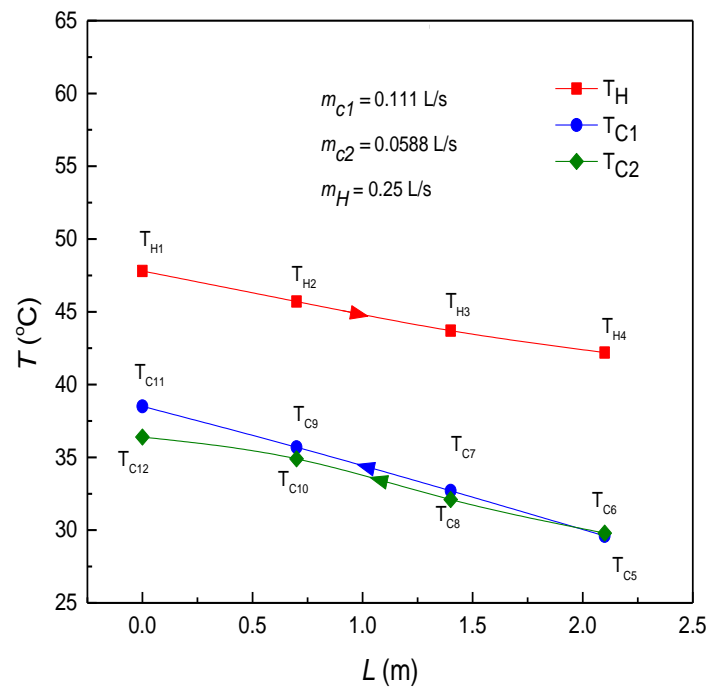

(c)Test 3

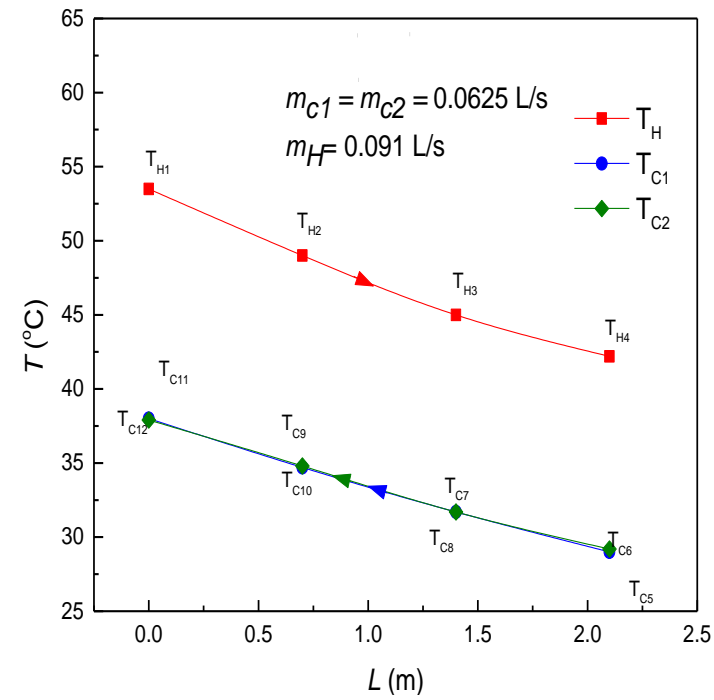

(b) test 2

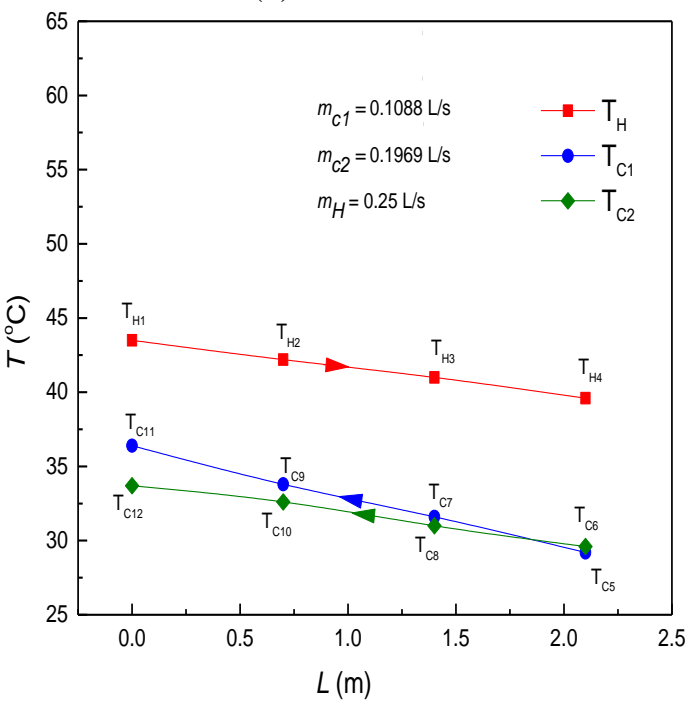

(d) test 4

Fig4. Variation of temperature along the length of TCTHE for counter flow arrangement

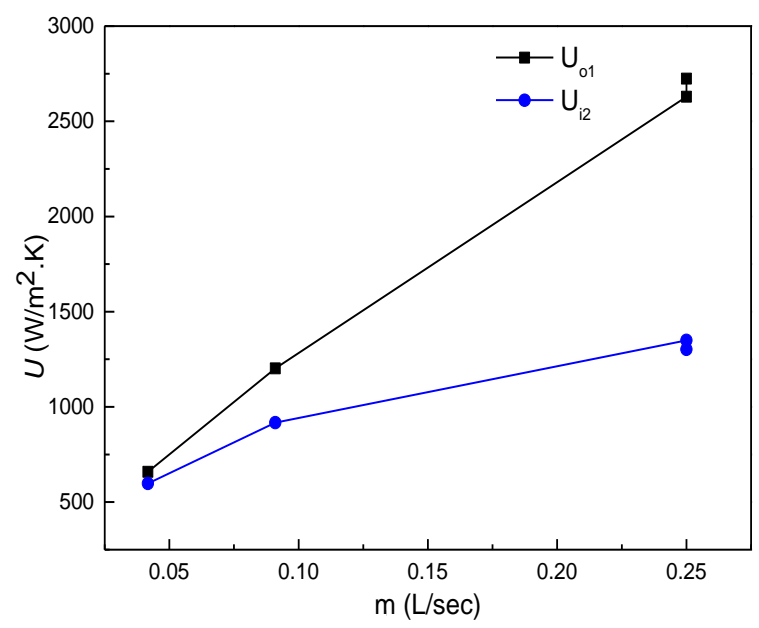

Fig5. variation of overall heat transfer coefficient with water mass flow rate

Theoretically, it is found that for the same heat transfer the length of TCTHE was found of $2.10 \mathrm{~m}$ while the length of double tube heat exchanger was $6.03 \mathrm{~m}$ which is near about $65 \%$ larger as compared to length of the TCTHE. Thus, the TCTHE provides large heat transfer area per unit length and better heat transfer efficiencies. Double tube heat exchanger requires more space compared to TCTHE. 
Table4. Data for mass flow rate and overall heat transfer coefficient

\begin{tabular}{|c|c|c|c|c|}
\hline $\begin{array}{c}\dot{m}_{H} \\
(\mathrm{~L} / \mathrm{sec})\end{array}$ & $\begin{array}{c}\dot{m}_{C 1} \\
(\mathrm{~L} / \mathrm{sec})\end{array}$ & $\begin{array}{c}\dot{m}_{C 2} \\
(\mathrm{~L} / \mathrm{sec})\end{array}$ & $U_{o 1}$ & $\mathrm{U}_{\mathrm{i} 2}$ \\
\hline 0.25 & 0.1088 & 0.1969 & $\left.\mathrm{~W} / \mathrm{m}^{2} . \mathrm{K}\right)$ & 2723.65 \\
\hline 0.25 & 0.111 & 0.0588 & 2628.65 & 1301.79 \\
\hline 0.091 & 0.0625 & 0.0625 & 1202.35 & 917.38 \\
\hline 0.0417 & 0.02778 & 0.02778 & 658.89 & 598.05 \\
\hline
\end{tabular}

\subsection{Verification of Experimental Data}

The experimental results of TCTHE is verified with that of theoretical results by plotting $N u$ vs. $R e$ curve as shown in Fig. 6. it is seen from this figure that the theoretical and experimental values are almost same. So, the results obtained by the designed TCTHE is acceptable and reliable. Fig. 7 shows the variation of Nusselt number with Reynolds number different tubes. It is seen from this figure that the convective heat transfer effect is higher for central and intermediate tube compared to outer tube which is also seen in temperature variation. It is because fluid in tube 1 and tube 2 contains increased turbulence comparative to tube 3 .

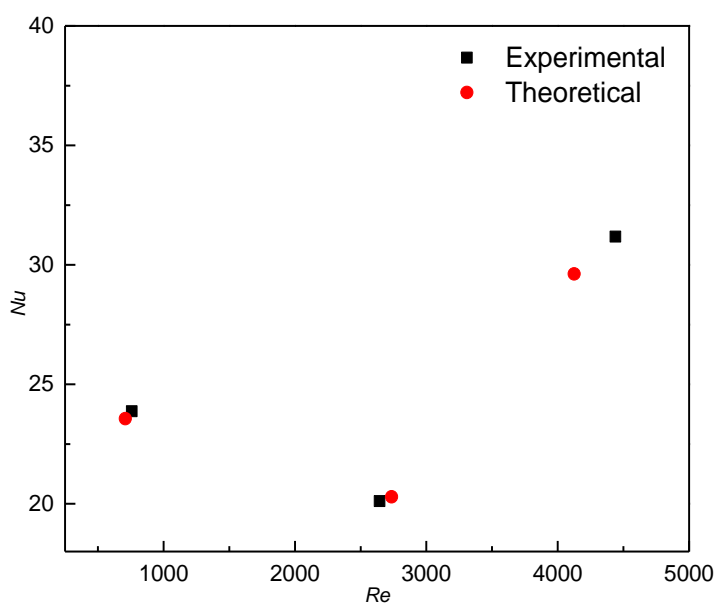

Fig6. Comparison of theoretical and experimental Nusselt number

\section{PRessure Drop}

Figure 8 shows the variation of pressure drop with Reynolds number. From the figure, it is observed that pressure drops are increases with Reynolds numbers for tube 1,2 and 3. For tube 1 (central tube) shows higher pressure drop than tube 2 and 3 because of diameter of tube. Since the diameter of central tube is smaller so produce more turbulence as well as pressure drop.

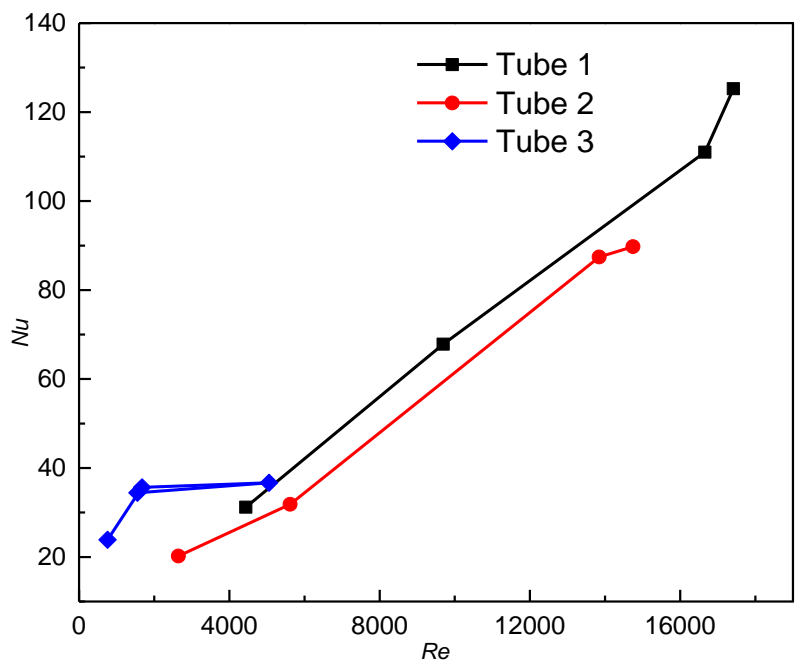

Fig7. variation of Nusselt number with Reynolds number for different tubes in TCTHE 


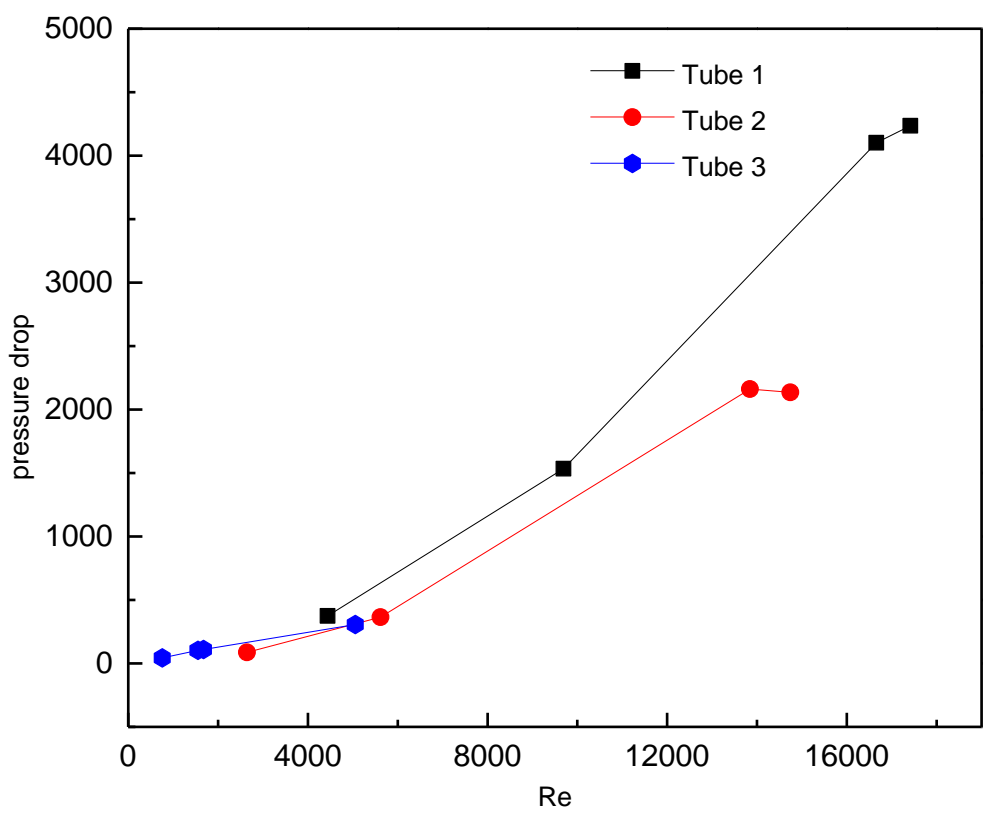

Fig8. Variation of Pressure drop with Reynolds number

\section{CONCLUSIONS}

The experimental study is conducted in laboratory demonstrates to investigate the heat transfer rate and the overall heat transfer coefficients for TCTHE. It is found that the heat transfer rate and overall heat transfer coefficient is much higher in TCTHE than double tube heat exchanger. TCTHE provides considerable amount of space and material saving as compared to double tube heat exchanger. It is also observed that heat transfer rate is higher at higher flow rate in inner tube, inner annular space and outer annular space.

\section{REFERENCES}

[1] Zuritz C. A.," On the design of triple concentric tube heat exchangers”, Journal of Food Process Engineering,1990,12,113-130.

[2] SekulicD.P., Shah R. K. "Thermal design theory of three fluid heat exchangers", Advances in Heat Transfer,1995,26,219-328.

[3] Unal A., "Theoretical analysis of triple concentric tube heat exchanger Part-1 Mathematical modeling", International Communication Heat mass Transfer,1998,25,949-958.

[4] Unal A., "Theoretical analysis of triple concentric tube heat exchanger Part-2 Case studies", International Communication Heat mass Transfer,2001,28,243-256.

[5] Batmaz E., SandeepK.P., "Calculation of overall heat transfer coefficients in a triple concentric tube heat exchangers", Heat Mass Transfer,2005,41,271-279.

[6] Radulescu S., Negoita I. L.,Onutu I.,"Heat transfer coefficient solver for a triple concentric tube heat exchanger in transition regime ",REV.CHIM,2012,63.

[7] Ghiwala T. M., MatawalaV.K., "Sizing of triple concentric pipe heat exchanger", SVMIT, Bharuch, 392001, Gujara, India.

Citation: Md. Anowar et al.(2017). Experimental Analysis of a Triple Concentric Tube Heat Exchanger, International Journal of Modern Studies in Mechanical Engineering (IJMSME), 3(3), pp.1-10 DOI: http://dx.doi.org/10.20431/2454-9711.0303001

Copyright: (๑) 2017 Md. Anowar This is an open-access article distributed under the terms of the Creative Commons Attribution License, which permits unrestricted use, distribution, and reproduction in any medium, provided the original author and source are credited 